\title{
Design and Development of Buck Chopper and Applications
}

\author{
K Vamsi Krishna ${ }^{1}$ | B Bindhu Madavi ${ }^{1}$ | A Anantha Saidatta ${ }^{1}$ A Ramakoti ${ }^{1}$ \\ ${ }^{1}$ Department of EEE, AITAM Engineering Colleg (Autonomous).Andhra Pradesh, India.
}

\section{To Cite this Article}

K Vamsi Krishna, B Bindhu Madavi, A Anantha Saidatta and A Ramakoti, "Design and Development of Buck Chopper and Applications", International Journal for Modern Trends in Science and Technology, Vol. 06, Issue 07, July 2020, pp.:69-72; https://doi.org/10,46501/IJMTST060610

\section{Article Info}

Received on 11-June-2020, Revised on 18-June-2020, Accepted on 21-June-2020, Published on 01-July-2020.

\section{ABSTRACT}

A Buck converter is the basic switched-mode power supply topology. The buck converter is type of DC to DC Converter that has an output voltage magnitude is less than the input voltage magnitude.The Buck converter produces voltage ranging from input voltage down to zero voltage. It is widely used throughout the industry to convert higher DC input voltage into DC output voltage.

The Buck converter is the most popular topology used to distribute power in complex systems e.g. computer motherboard, broadband communication board, etc...The output voltage is typical of the same polarity of the input and is the lower than the input. Such as non-inverting buck converter use a single inductor for the buck inductor mode. The buck converter has the filter inductor on the output side, which provides a smooth continues output current waveform to the load. This could be considered a qualitative benefit but requires special considerations for big load transients.

Copyright (C) 2014-2020 International Journal for Modern Trends in Science and Technology

DOI: https://doi.org/10.46501/IJMTST060610

\section{INTRODUCTION}

The main applications of the circuit are in regulated dc power supplies, where a negative polarity output may be desired with respect to the common terminals of the input voltage and the average output is lower than dc input voltage. The output voltage is controlled by controlling the switch duty cycle. The ratio of the output voltage to input voltage is given by

$$
\mathrm{Vo} / \operatorname{Vin}=\mathrm{D}^{*}(1-\mathrm{D})=\operatorname{Iin} / \text { Io. }
$$

Where, Vo and Vin are the output and input voltages, respectively. The term Io and Iinare the output and input currents, respectively. The term $\mathrm{D}$ is the duty ratio and defined as the ratio and defined as the ratio of the ratio of the on time of the switch to the switching period. This shows the output voltage to be the higher or lower the input voltage, based on the duty ratio $\mathrm{D}$. The dc-dc converter inputs an unregulated dc voltage, input and outputs a constant or regulated voltage the regulators can be mainly classified into linear and switching regulators.

All regulators have a power transfer stage and a control circuitry to sense the output voltage and adjust the power transfer stage to maintain the constant output voltage. since a feedback loop is necessary to maintain regulation, some type compensation is required to maintain loop stability.

\section{Circuit diagram}

The buck converter is capable of producing a dc output voltage which is smaller in magnitude than 
the dc input voltage. The arrangement for the basic buck converter as shown in figure 1 .

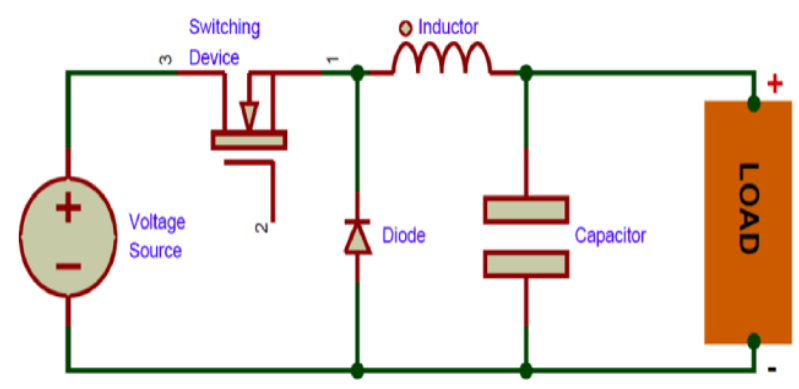

When switch is $\mathrm{S}$ on the input voltage is applied across the inductor and the current in inductor $\mathrm{L}$ rises linearly. At this time the capacitor (C) supplies the load current, and it is partially discharged . During the second interval when the transistor is off, the voltage across the inductor reverses in polarity and the diode conducts. During this interval, the energy stored in the inductor supplies the load and, additionally, recharges the capacitor. The steady inductor current and voltage waveform is shown in fig2.

Using the inductor volt balance principle to find the steady state output voltage equation yields

The working of a buck converter can be broken down into a few steps.

STEP - 1:

The switch turns on and lets current flow to the output capacitor, charging it up. Since the voltage across the capacitor cannot rise instantly, and since the inductor limits the charging current, the voltage across the cap during the switching cycle is not the full voltage of the power source.

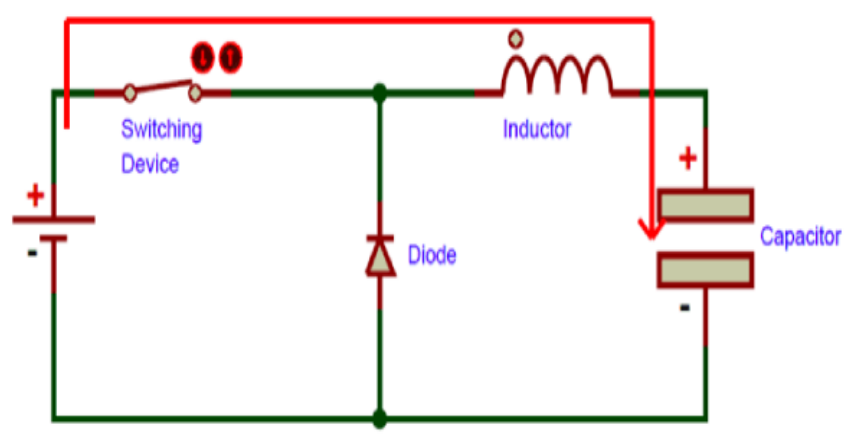

STEP - 2:

The switch now turns off. Since the current in an inductor cannot change suddenly, the inductor creates a voltage across it. This voltage is allowed to charge the capacitor and power the load through the diode when the switch is turned off, maintaining current output current throughout the switching cycle.

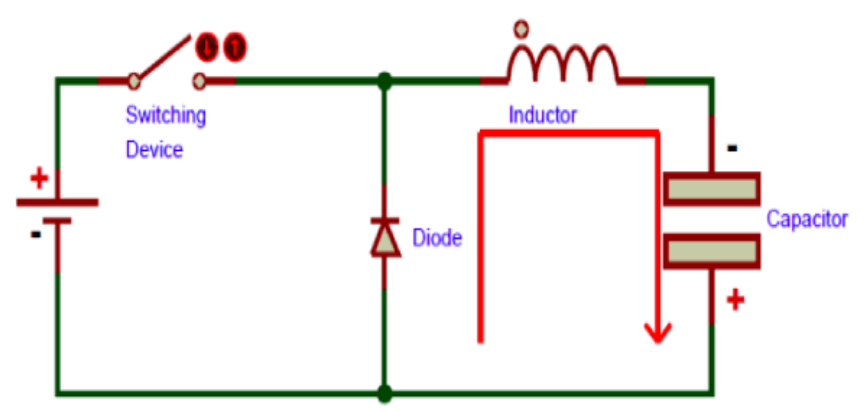

These two steps keep repeating many thousands of times a second, resulting in continuous output.

\section{Designing a Buck Converter}

\section{STEP - 1}

Determine the input voltage and the output voltage and current.

The duty cycle of the converter is given by:

$\mathrm{DC}=\mathrm{V}_{\text {out }} / \mathrm{V}_{\text {in }}$

\section{STEP - 2}

Determine the output power, that is, the product of the output voltage and current. This is also the input power, by the law of conservation of energy (though not exactly so - nothing is a hundred percent efficient!).

\section{STEP - 3}

Now divide the output power by the selected switching frequency in order to get the power transferred per pulse.

Since it is easier to talk about inductors in terms of energy, we can assume now that the output power is simply the output energy per second. So if the output of our converter is 30 Watts, then we can say that the output energy is thirty Joules every second.

\section{STEP - 4}

Now that we have the energy per pulse, we can calculate the inductance using the input current and the energy:

$\mathrm{L}=2 \mathrm{E} / \mathrm{I}^{2}$

Where $\mathrm{E}$ is the energy transferred per pulse and I is the square of the input current.

Using the values of the inductance, frequency and duty cycle, we can now get to work building a simple boost converter. 


\section{A. BUCK CONVETER}

- 1Theory of operation

- 2 Concept

- 2.1Continuous mode

- 2.2Discontinuous mode

B. Theory of operation

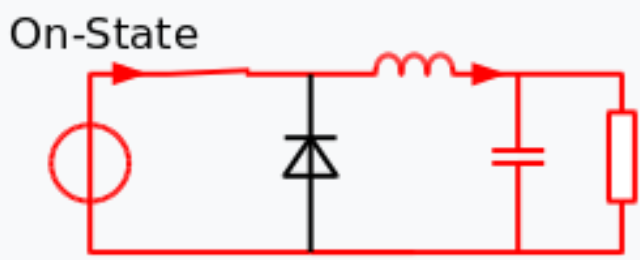

\section{Off-State}

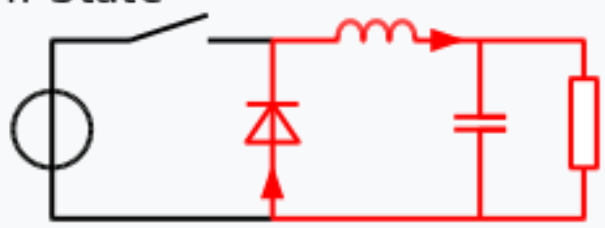

Fig. 2: The two circuit configurations of a buck converter: on-state, when the switch is closed; and off-state, when the switch is open (arrows indicate current according to the direction conventional current model).

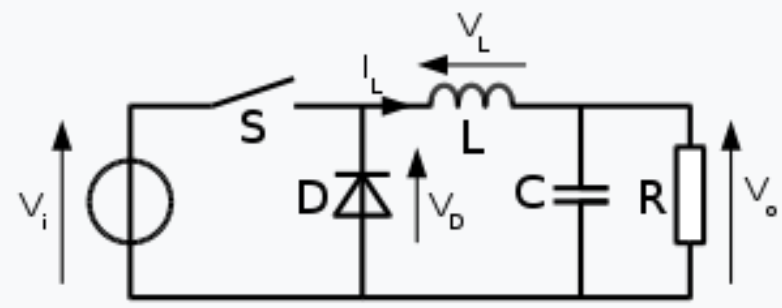

Fig. 3: Naming conventions of the components, voltages and current of the buck converter.

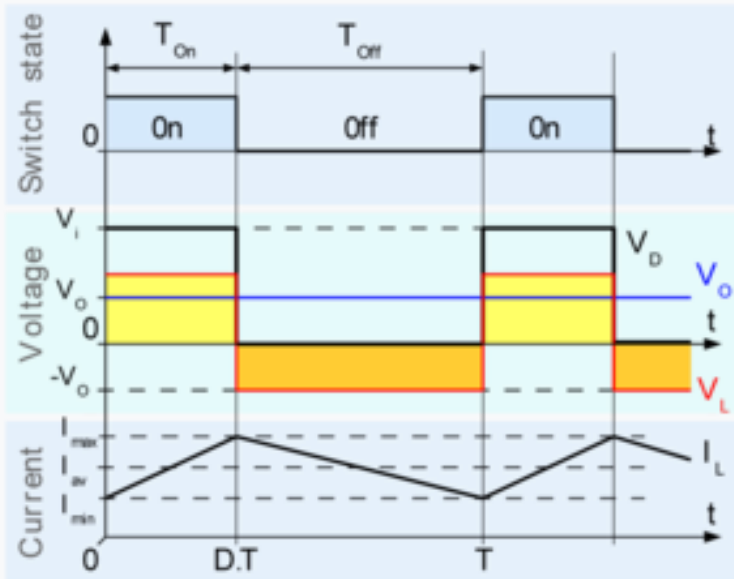

Fig. 4: Evolution of the voltages and currents with time in an ideal buck converter operating in continuous mode.
The basic operation of the buck converter has the current in an inductor controlled by two switches (usually a transistor and a diode). In the idealised converter, all the components are considered to be perfect. Specifically, the switch and the diode have zero voltage drop when on and zero current flow when off, and the inductor has zero series resistance. Further, it is assumed that the input and output voltages do not change over the course of a cycle.

\section{CONCEPT}

The conceptual model of the buck converter is best understood in terms of the relation between current and voltage of the inductor. Beginning with the switch open (off-state), the current in the circuit is zero. When the switch is first closed (on-state), the current will begin to increase, and the inductor will produce an opposing voltage across its terminals in response to the changing current. This voltage drop counteracts the voltage of the source and therefore reduces the net voltage across the load. Over time, the rate of change of current decreases, and the voltage across the inductor also then decreases, increasing the voltage at the load. During this time, the inductor stores energy in the form of a magnetic field. If the switch is opened while the current is still changing, then there will always be a voltage drop across the inductor, so the net voltage at the

\section{SIMULATION MODEL}

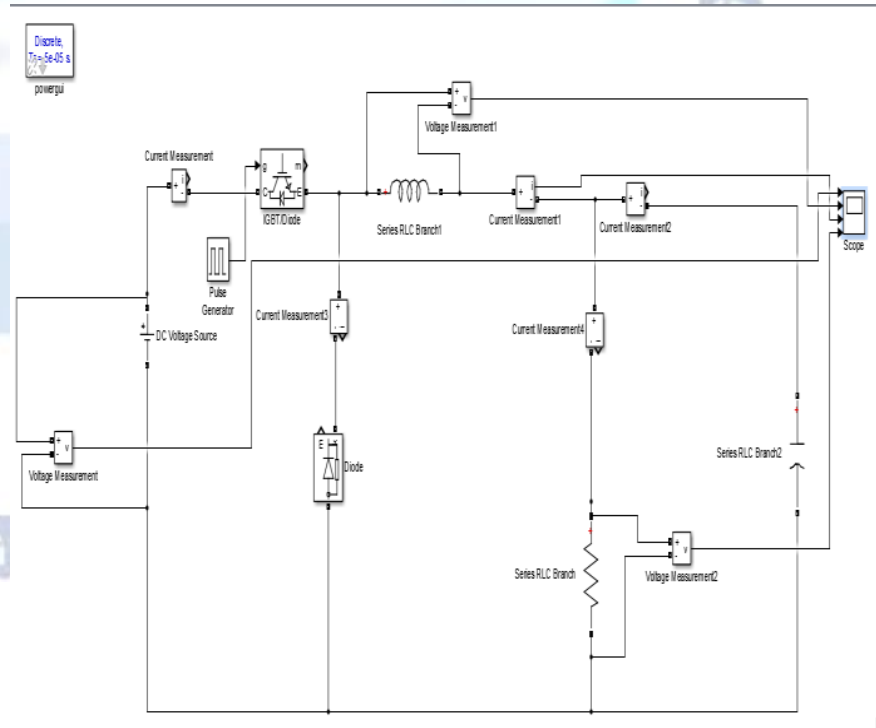




\section{OBSERVATIONS:}

\begin{tabular}{|l|l|l|l|}
\hline $\begin{array}{l}\text { Sl. } \\
\text { No. }\end{array}$ & Parameter & Specification & Value \\
\hline 1 & Output Power & Pout & 100 \\
\hline 2 & Output Voltage & $V_{\text {out }}$ & 12 \\
\hline 3 & Input Voltage & $V_{\text {in }}$ & 24 \\
\hline 4 & $\begin{array}{l}\text { Switching } \\
\text { Frequency }\end{array}$ & $F_{\text {sw }}$ & $20 \mathrm{KHz}$ \\
\hline 5 & $\begin{array}{l}\text { OutputVoltage } \\
\text { Ripple }\end{array}$ & $\Delta V_{o}$ & 0.12 \\
\hline 6 & $\begin{array}{l}\text { Input Current } \\
\text { peak ripple }\end{array}$ & $\Delta I_{L}$ & 4.56 \\
\hline
\end{tabular}

Converter specifications for design.

\section{OUTPUT WAVEFORMS:}

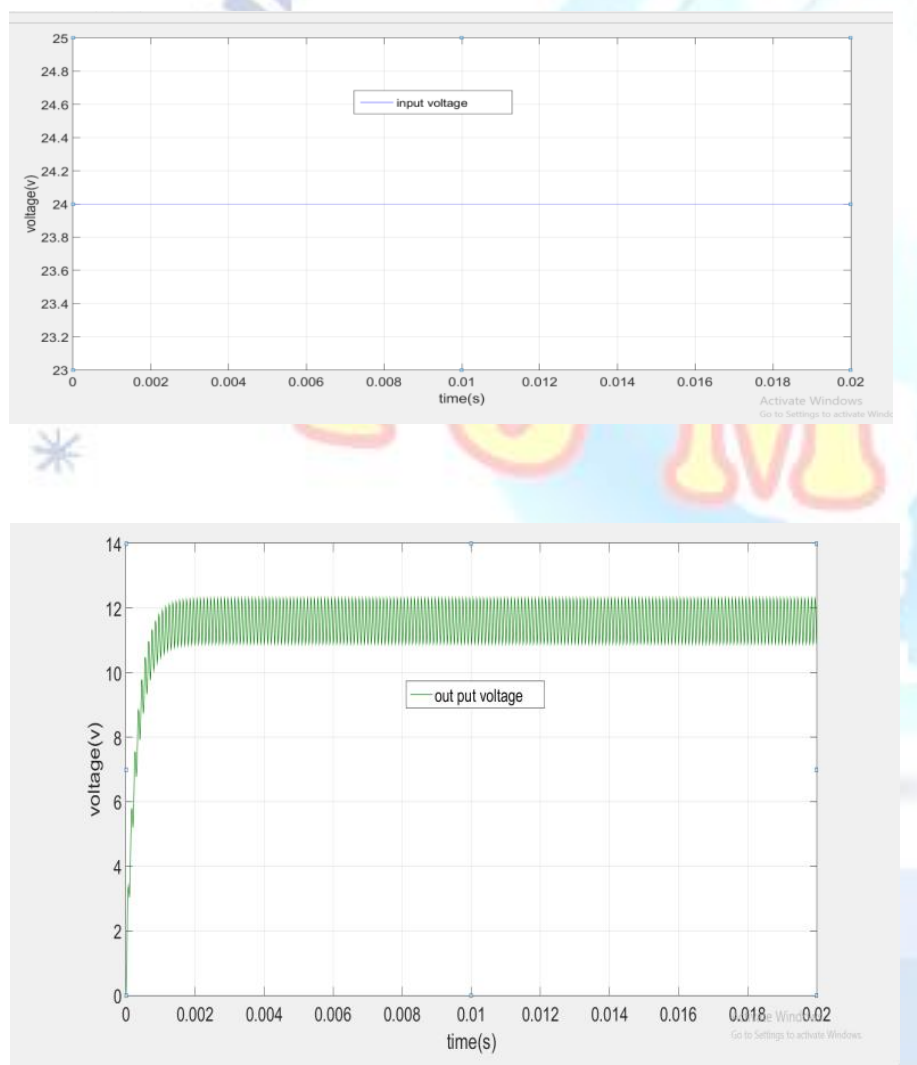

\section{CONCLUSION}

This project report has provided a brief introduction to buck converters. A dc-dc buck converter is introduced between PV system and load to meet the dynamic energy requirement of the load in an efficient way. It is observed that buck converter largely increases the system efficiency. To $g$ et large efficiency of converter, reduces the conduction losses and voltage spikes occurs across the power switch. The mathematical model is derived from the system equations and provide an accurate representation of the buck converter. The system is also discussed in order to permit the use of the controller tuning tools provided my MATLAB. This converter can operate with a very good input $\mathrm{PF}$. By considering the relationship between key parameters graphs of steady state characteristics are obtained. Audio amplifiers and motor control circuits have a great deal in common with buck converters.

\section{REFERENCES}

[1] Rashid, H. Muhammad, Power Electronics - Circuits, Devices and Applications, Prentice Hall India, 2004

[2] Bimbra, P. S., Power Electronics, Khanna Publishers, 2007

[3] Liu, Kwang-Hwa and Lee, F. C., Zero Voltage Switching technique in DC/DC Converters, IEEE Transactions on Power Electronics, 1990, p293 - p304

[4] Szychta, Elzbieta, Multiresonant ZVS Boost Converter, Electrical Power Quality and Utilisation Journal, Vol XI, No. 2 2005, p65 - p71

[5] Tabisz A. Wojciech, Lee, F. C., Zero Voltage Switching Multiresonant Technique, IEEE Transactions on Power Electronics, p $9-$ p 17
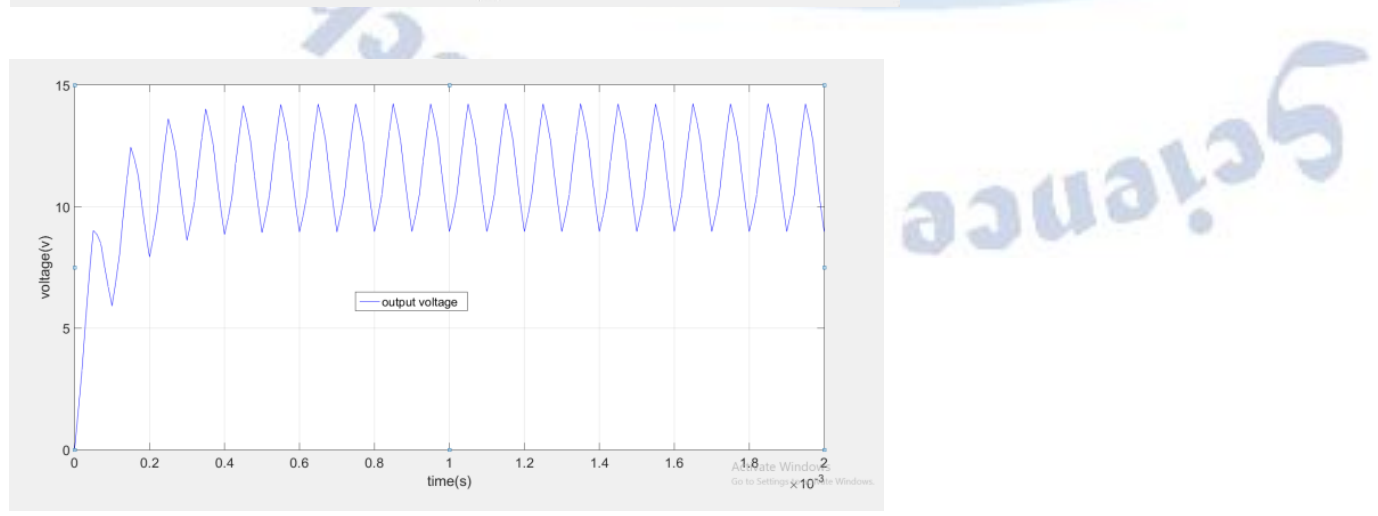